\title{
Threshold level of protein kinase A activity and polarized growth in Mucor rouxii
}

\author{
Elba Pereyra, Cynthia Mizyrycki and Silvia Moreno
}

Departamento de Química Biológica, Facultad de Ciencias Exactas y Naturales, Universidad de Buenos Aires, Ciudad Universitaria, Pabellón 2, Piso 4, 1428 Buenos Aires, Argentina
Author for correspondence: Silvia Moreno. Tel: +54 114576 3342. Fax: +54 1145763342. e-mail:smoreno@qb.fcen.uba.ar

\begin{abstract}
A model system to study the involvement of CAMP-mediated regulation of a cellular process such as hyphal morphogenesis was investigated. Impairment of polarized growth was observed when Mucor rouxii sporangiospores were grown in the presence of $\boldsymbol{N}^{6}$-CAMP analogues and of SQ 65,442, a CAMP phosphodiesterase inhibitor. Together with an effect on isodiametric growth, there was increased pigmentation, increased cell fragility and loss of cell adhesiveness. The total effect on morphology was attained even after adding the compounds shortly before germ-tube emergence; when added after this time growth continued in a non-polarized form and rounding of the germ tip was observed. The morphological effect was observed under all the nutritional and environmental conditions studied (aerobic conditions and defined medium with maltose or glucose, Casamino acids medium with glucose, or rich medium; anaerobic conditions with rich medium; and following a shift from anaerobiosis to aerobiosis). The time of germ-tube emergence, and the size of the cell at this time, was dependent on the growth medium. Protein kinase A (PKA) specific activity was followed during the germination process under three growth conditions. It was found that the total activity of PKA correlated with differentiation and not with growth, and that the total specific activity at the time of germination was the same, independent of the culture medium. The time of germ-tube emergence correlated with the time of attainment of a threshold level of PKA total specific activity. The concentration of dibutyrylCAMP needed to promote isodiametric growth correlated with the total units of activity of PKA to be activated per cell. It was concluded that PKA is involved in the morphogenetic process of the fungus grown under all the nutritional and ambient conditions tested.
\end{abstract}

Keywords: cAMP, morphogenesis, Mucor rouxii, protein kinase A, polarized growth

\section{INTRODUCTION}

Three basically different models have been proposed to explain hyphal morphogenesis, the polarized form of growth that produces a tubular cell. Each model invokes different morphogenetic criteria: 1, the changing in the physical properties of the cell wall (Sietsma \& Wessels, 1994); 2, the moulding of the hyphal shape by the expanding cytoplasm (Heath, 1994; Money, 1994) and 3 , the pattern of vesicle migration or hyphoid model

Abbreviations: Cl-930, 3(2H)-pyridazinone,4,5-dihydro-6-[4-(1H-imidazol-1-yl) phenyl-5-methylmonohydrochloride; dbut-cAMP, dibutyrylCAMP; IBMX, isobutyl-methylxanthine; PDE, phosphodiesterase; PKA, CAMP-dependent protein kinase; SQ 65,442, 1-ethyl-4-(ethylthio)-1Hpyrazolo[3,4-b]-pyridine-5-carboxylic acid ethyl ester.
(Bartnicki-García, 1990, 1996). None of the current models explaining hyphal morphogenesis define the precise biochemical reaction(s) that confers polarity to a hypha. Recently, results derived from genetic approaches have indicated that the signalling systems controlling filamentous growth are multiple and conserved between distantly related fungi. In particular, cAMP signalling has been demonstrated to mediate fungal development, although target effectors have not yet been suggested (Kronstad, 1997; Alspaugh et al., 1998; Hamer \& Talbot, 1998; Kronstad et al., 1998; Madhani \& Fink, 1998; Yang \& Dickman, 1999).

The fungus Mucor rouxii exhibits dimorphic growth; under aerobic conditions it grows as a typical mycelium, and under anaerobiosis the growth is as yeast-like cells 
(Bartnicki-García \& Nickerson, 1962). The possible role of cAMP in the morphogenetic process of Mucor has previously attracted the attention of a number of researchers (Orlowski, 1991, 1995). We have reported that in the presence of dibutyryl-cAMP (dbut-cAMP) the sporangiospores from $M$. rouxii grow isodiametrically and that polarized growth is prevented without alteration of growth parameters (Pereyra et al., 1992).

To study in more detail the transduction pathway involved in the effect of dbut-cAMP upon $M$. rouxii morphology, we decided to investigate the involvement of cAMP-dependent protein kinase (PKA) in this process. M. rouxii PKA has been thoroughly characterized (Moreno \& Passeron, 1980; Moreno et al., 1983; Paveto et al., 1989; Guthmann et al., 1990) and the levels of its subunits have been measured during the time course of spore germination in rich medium (Rossi \& Moreno, 1994).

In this report we clarify three points that will help to establish a model system in which to study the involvement of cAMP-mediated phosphorylation-dependent regulation of a cellular process such as hyphal morphogenesis: 1, PKA is involved in the morphogenetic process; 2, the impairment of polarized growth by cAMP analogues is a general effect which can be observed under diverse environmental and nutritional conditions; 3 , the concentration of PKA seems to be critical for the differentiation of the germinated sporangiospore.

\section{METHODS}

Strain, growth conditions and microscopic observations. Mucor rouxii (NRRL 1894) was used throughout. Spores, obtained and stored as described by Haidle \& Storck (1966), were inoculated at a concentration of $10^{6}$ spores $\mathrm{ml}^{-1}$. The culture volume was $4 \mathrm{ml}$ when it was used for microscopic observations, $40 \mathrm{ml}$ for growth measurements and 100-500 ml for enzymic assays. The following media were used: defined media consisting of mineral-salt solution supplemented with vitamins (Bartnicki-García \& Nickerson, 1962) and 2\% glucose (DMG) or $2 \%$ maltose (DMM) as carbon sources; defined medium with $2 \%$ glucose and $0.2 \%$ Casamino acids (DMCG) or complex medium with $0.3 \%$ yeast extract, $1 \%$ peptone and $3 \%$ glucose (YPG; Bartnicki-García \& Nickerson, 1962). Stock solutions were filter-sterilized before addition to the culture in appropriate amounts. Flasks were incubated in a gyratory shaker at 100 r.p.m. and at $28^{\circ} \mathrm{C}$ for variable periods of time. Anaerobic growth was performed in stoppered Erlenmeyer flasks continually flushed with $100 \%$ $\mathrm{CO}_{2}$. For the experiments of shift from anaerobic to aerobic growth, yeast-like cells growing in YPG under anaerobiosis were filtered and incubated in DMG medium under aerobic conditions.

Samples of cultures were withdrawn and observed under the light microscope. Morphologies were classified as follows: M, when cells germinated normally yielding a typical mycelium (Fig. 1a); P, when the effect on morphology was partial and the observed forms comprised round cells, cells with reduced hyphal branching, thicker hyphae with swollen tips and forms consisting of rounded cells in a chain (Fig. 1b) and T, when the effect was total and the complete population consisted of rounded cells without buds (Fig. 1c). About 100 cells were scored for each experiment.

Protein kinase assay and protein determination. Samples containing approximately the same wet weight $(200 \mathrm{mg})$ of the cultures grown for different times in the various culture media were used. Zero time points correspond to an equivalent amount of spores taken directly from the stock solution in water. The cells in the samples were harvested by filtration and processed immediately. Crude extracts were prepared by vortexing the cells three times for $1 \mathrm{~min}$ at $4{ }^{\circ} \mathrm{C}$ with $1 \cdot 2 \mathrm{~g}$ glass beads (460-600 $\mu \mathrm{m}$ diameter) and $0.6 \mathrm{ml}$ homogenization buffer $(50 \mathrm{mM}$ potassium phosphate, $\mathrm{pH} 6 \cdot 8,5 \mathrm{mM}$ EDTA, $3 \mathrm{mM}$ EGTA, $120 \mathrm{mM} \mathrm{NaCl}, 10 \mathrm{mM}$ 2-mercaptoethanol, $1 \mathrm{mM}$ PMSF, $3 \mu \mathrm{g}$ antipain $\mathrm{ml}^{-1}$ and $1 \mathrm{mM}$ benzamidine. Protein kinase assays were performed immediately. Methodological considerations for measuring total PKA activity in the extracts and for taking this value as a measure of the total level of PKA were given before (Rossi \& Moreno, 1994). The total activity of PKA was determined by assaying its phosphotransferase activity in the presence of cAMP, using kemptide as the substrate, one unit being defined as the amount of enzyme catalysing the incorporation of $1 \mathrm{nmol}$ phosphate to kemptide during $10 \mathrm{~min}$ at $30^{\circ} \mathrm{C}$. The samples to be tested were diluted 20-40-fold in the same extraction buffer, but omitting the $\mathrm{NaCl}$ and adding $0.9 \mathrm{mg} \mathrm{BSA} \mathrm{ml}^{-1}$. The assay was started by mixing the diluted samples (in the range $2-4 \mu \mathrm{g}$ total protein) with assay mixture to give the following final concentrations of assay components: $50 \mathrm{mM}$ potassium phosphate, $\mathrm{pH} 6 \cdot 8,75 \mu \mathrm{M}$ kemptide, $0 \cdot 1 \mathrm{mM}\left[\gamma^{-32} \mathrm{P}\right] \mathrm{ATP}$ (1300 c.p.m. pmol $^{-1}$ ), $0.5 \mathrm{mM}$ EGTA, $0.1 \mathrm{mM}$ EDTA, $1 \mathrm{mM} 2-$ mercaptoethanol and $10 \mu \mathrm{M}$ cAMP. After $10 \mathrm{~min}$ at $30^{\circ} \mathrm{C}$, aliquots were processed according to the phosphocellulosepaper method (Roskoski, 1983). Reaction rates for the enzymic assays were linear with time and proportional to enzymeprotein concentration. Data points are the means of quadruplicate determinations. All experiments were repeated at least three times with independent preparations. Representative experiments are shown for each case.

Soluble protein was determined by the Bradford assay (Bradford, 1976), using BSA as the standard.

Chemicals. $\left[\gamma^{32} \mathrm{P}\right]$ ATP was from New England Nuclear; kemptide, cAMP analogues, papaverine, isobutyl-methylxanthine (IBMX), theophylline, and dipyridamole were from Sigma; CI-930 (3(2H)-pyridazinone,4,5-dihydro-6-[4- $(1 H$ imidazol-1-yl) phenyl-5-methylmonohydrochloride) was a gift from Warner Lambert, Ann Arbor, MI; and SQ 65,442 (1ethyl-4-(ethylthio)-1H-pyrazolo[3,4- $b]$-pyridine-5-carboxylic acid ethyl ester) was a gift from E. R. Squibb and Sons, Princeton, NJ, USA. Stock solutions $(10 \mathrm{mM})$ of each compound were prepared as follows: cAMP analogues, papaverine, IBMX and CI-930 in water; dipyridamole and SQ 65,442 in ethanol. Other reagents were of analytical grade.

\section{RESULTS AND DISCUSSION}

\section{Effect of CAMP analogues and phosphodiesterase (PDE) inhibitors on morphology}

Different cAMP analogues and cAMP PDE inhibitors were added to the culture medium of $M$. rouxii sporangiospores to investigate the effect they had on the morphology adopted by spores upon germination. The analogues used were: $\mathrm{N}^{6}$-benzoyl-cAMP and $\mathrm{N}^{6}$-monobutyryl-cAMP. dbut-cAMP was included as a control, 
Table 1. In vivo effect of CAMP analogues and PDE inhibitors

M. rouxii sporangiospores were grown in DMG with the addition of the indicated compounds; morphologies were observed after $16 \mathrm{~h}$ growth. Representative images of morphologies are shown in Fig. $1(\mathrm{a}-\mathrm{d})$. Drug responses were controlled for solvent effects. Abbreviations are: $N^{6}$-ben-cAMP, $N^{6}$-benzoyl-cAMP; $N^{6}$-but-cAMP, $N^{6}$-monobutyryl-cAMP; $\mathrm{O}^{2}$-but-cAMP, $\mathrm{O}^{2}$-monobutyryl-cAMP; $\mathrm{M}$, mycelial growth; $P$, partial effect; $T$, total effect.

\begin{tabular}{|lcc|}
\hline Added compound & Concn $(\mathbf{m M})$ & Morphology \\
\hline None & 0 & $\mathrm{M}$ \\
cAMP analogues & & \\
$N^{6}$-ben-cAMP & $0 \cdot 15$ & $\mathrm{M}$ \\
& $0 \cdot 3$ & $\mathrm{P}$ \\
& $0 \cdot 6$ & $\mathrm{~T}$ \\
$\mathrm{~N}^{6}$-but-cAMP & $1 \cdot 0$ & $\mathrm{~T}$ \\
& $0 \cdot 5$ & $\mathrm{P}$ \\
& $1 \cdot 0$ & $\mathrm{P}$ \\
dbut-cAMP & $1 \cdot 5$ & $\mathrm{~T}$ \\
$\mathrm{O}^{2}$-but-cAMP & $3 \cdot 0$ & $\mathrm{M}$ \\
Butyrate & $0 \cdot 15$ & $\mathrm{~T}$ \\
PDE inhibitors & $0 \cdot 15$ & $\mathrm{M}$ \\
Papaverine & $0 \cdot 3$ & $\mathrm{M}$ \\
IBMX & & \\
Theophylline & $0 \cdot 1$ & $\mathrm{M}$ \\
CI 930 & $1 \cdot 0$ & $\mathrm{M}$ \\
Dipyridamole & $1 \cdot 0$ & $\mathrm{M}$ \\
SQ 65,442 & $1 \cdot 0$ & $\mathrm{M}$ \\
& $1 \cdot 0$ & $\mathrm{M}$ \\
& $0 \cdot 01$ & $\mathrm{M}$ \\
& $0 \cdot 05$ & $\mathrm{~T}$ \\
\hline
\end{tabular}

as well as the two products that could be derived from its hydrolysis: $\mathrm{O}^{2}$-mono-butyryl-cAMP and butyrate. Six different PDE inhibitors were selected from a list of drugs whose in vitro effect on $M$. rouxii PDE activity had already been tested (Tomes \& Moreno, 1990): papaverine, CI-930, dipyridamole and SQ 65,442 displayed no secondary effect on PKA activity in vitro (Tomes et al., 1993); IBMX and theophylline were assayed because they are the most widely used PDE inhibitors in the literature.

The results are summarized in Table 1 and representative images are shown in Fig. $1 . N^{6}$-benzoyl-cAMP at $0.6 \mathrm{mM}$ and $N^{6}$-monobutyryl-cAMP at $1.5 \mathrm{mM}$ promoted isodiametric growth of $M$. rouxii sporangiospores (Fig. 1b, c). At 0.15 mM dbut-cAMP, total effect was observed as already reported (Pereyra et al., 1992). Two controls were performed with $\mathrm{O}^{2^{\prime}}$-monobutyrylcAMP and butyrate, assayed at the maximal concentrations that could be derived from the complete hydrolysis of $0.15 \mathrm{mM}$ dbut-cAMP. None of these compounds had an effect on morphology, indicating that the effects of dbut-cAMP are not due to these two hydrolytic products. The results observed in vivo are in accordance with those previously reported in vitro (Paveto et al., 1989), which indicated that these two cAMP analogues are potent activators of PKA. dbutcAMP is a very poor activator of PKA, since the concentration required to produce half-maximal activation of $M$. rouxii PKA is around 300-fold lower than for the two $N^{6}$-cAMP analogues. This low potency in the activation of PKA has already been reported for higher eukaryotic holoenzymes (Øgreid et al., 1985). However, its potency can be adequately explained by a sixfold increase in the endogenous cAMP levels (unpublished results). Although the concentration of PDE inhibitor required to produce $50 \%$ inhibition of hydrolysis of $1 \mu \mathrm{M}$ cAMP by the high-affinity cAMP PDE from the fungus is quite low (in the range of $1 \mathrm{mM}$; Tomes \& Moreno, 1990 and unpublished results), it has been reported to be a compound hydrolysed by the PDEs with a very small turnover (Van Haastert et al., 1983, Braunmann et al., 1986).

The only PDE inhibitor that promoted an effect on morphology at the concentrations assayed was SQ 65,442 . The total effect was attained at $0 \cdot 1 \mathrm{mM}$ (Fig. 1d), with a morphology similar to the one observed with $N^{6}$ cAMP analogues and with dbut-cAMP (Fig. 1c), except for a slight impairment of growth. Two observations guarantee that the lack of polarized growth observed in the presence of SQ 65,442 (see Table 1 and Fig. 1d) was not the result of growth impairment: 1, cells had a constant and sustained increase in diameter throughout the experiment and 2, they attained a diameter far larger than the one displayed by control cells at the time of germ-tube or bud emergence. The result observed with SQ 65,442 is in accordance with the fact that this compound is the best $M$. rouxii $\mathrm{PDE}$ inhibitor. The $\mathrm{IC}_{50}$ for the hydrolysis of $1 \mu \mathrm{M}$ cAMP was around $0.01 \mathrm{mM}$, at least an order of magnitude smaller than the $\mathrm{IC}_{50}$ for the rest of the compounds assayed (Tomes \& Moreno, 1990). The inhibitor has the advantage of being a lipophilic compound. It is not surprising that $M$. rouxii is insensitive to IBMX and to theophylline since it has been reported that PDE from another lower eukaryote, Saccharomyces cerevisiae, is also relatively insensitive to standard PDE inhibitors (Van Lookeren-Campagne et al., 1990).

\section{Characterization of the morphopoietic effect of CAMP analogues}

$M$. rouxii sporangiospores grown in the presence of cAMP analogues or SQ 65,442 have several characteristics, besides the isodiametric growth, that are worth summarizing: 1, increased pigmentation that can be observed macroscopically (isodiametrically growing cultures are slightly yellow while control ones are white) 2 , increased fragility, not prevented by osmotic stabilization of the growth medium (Pereyra et al., 1992); 3, loss of the typical adhesiveness that begins to be observed in the germling stage of control growth (compare Figs 1e and c). 

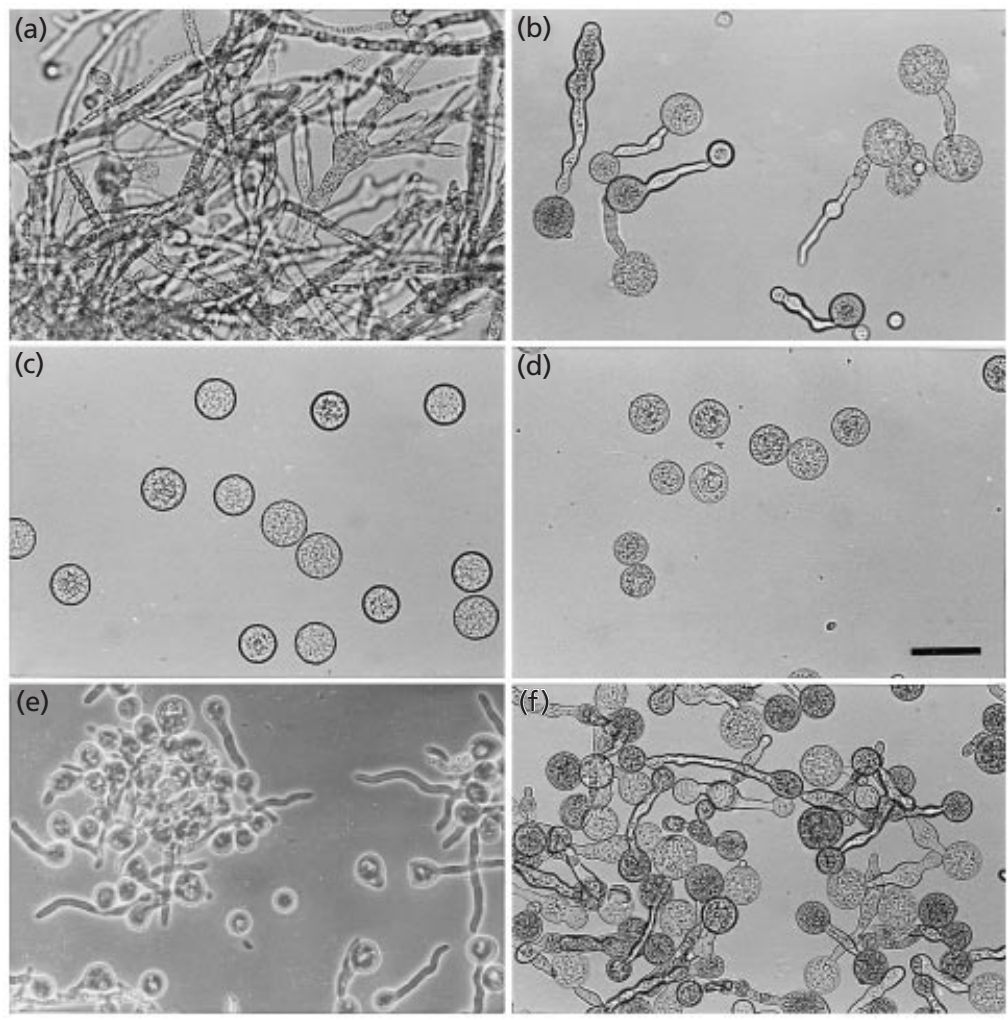

Fig. 1. Morphology of $M$. rouxii grown under different conditions. (a) Control medium DMG without additions, $16 \mathrm{~h}$, indicated as $M$ in Table 1. (b, c) Partial (b) and total (c) effects observed at $16 \mathrm{~h}$ growth with different additions (see Table 1, morphologies indicated as $\mathrm{P}$ and $\mathrm{T}$, respectively). (d) Total effect observed at $16 \mathrm{~h}$ upon addition of $0.1 \mathrm{mM}$ SQ 65,442 . (e) Cells grown in control medium DMG up to $7 \mathrm{~h}$. (f) Cells grown up to $7 \mathrm{~h}$ in control medium DMG and from 7 to $16 \mathrm{~h}$ with added $0.15 \mathrm{mM}$ dbut-cAMP. Bar, $28 \mu \mathrm{m}$.

There are examples in the literature correlating all of these characteristics to cAMP signal-transduction pathways. Increased carotene pigmentation has already been described to occur upon addition of dbut-cAMP to Mucor mucedo and Mucor hiemalis (Jones \& Bu'Lock, 1977) and signal transduction by cAMP has been suggested to cross-talk with carotenogenesis in fungi (Dandekar \& Modi, 1980; Hohl et al., 1992). Neurospora crassa cells, carrying a mutation in the regulatory subunit of PKA (Bruno et al., 1996) are extremely fragile and show thick cell walls, as has been observed ultrastructurally for $M$. rouxii cells grown with cAMP analogues (to be published elsewhere). Regarding cell adhesiveness, it has been already reported that cAMP is an important intracellular modulator of cell adhesion in mammalian cells. Glass \& Kreisberg (1993) observed that cAMP elevation in cultures of mesangial cells caused loss of adhesion, shape change towards rounded cells, microfilament fragmentation and myosin-lightchain dephosphorylation. The diversity of cell types exhibiting similar changes suggested to these authors that there could be a common underlying mechanism regulating cytoskeletal structure and adhesion (Glass \& Kreisberg, 1993 and references therein).

\section{Effect of time of addition of compounds to the culture medium}

The effects of cAMP analogues or PDE inhibitor on morphology described until now (Pereyra et al., 1992 and Table 1) were observed upon addition of the compound $30 \mathrm{~min}$ after the inoculation of sporangio- spores into the culture medium. To investigate the effect these compounds had on the germination process, experiments were performed in which $0.6 \mathrm{mM} \mathrm{N} \mathrm{N}^{6}$ benzoyl-cAMP or $0.15 \mathrm{mM}$ dbut-cAMP were added to the culture medium at $0,1,3,5$, and $7 \mathrm{~h}$ of growth. The morphologies observed at $16 \mathrm{~h}$ of growth were identical to those of Fig. 1c, no matter when the analogues were added, as long as it was before the germ-tube emergence (before 6 h). Once germination had begun (7 h; Fig. 1e) a severe effect on morphology was also observed (Fig. 1f); the images suggested that growth after the addition of the analogue tends to continue in a non-polarized form. The same results were observed when performing the experiment in the presence of $0 \cdot 1 \mathrm{mM}$ SQ 65,442 (data not shown). These results suggest that the process impaired by cAMP analogues or PDE inhibitor, leading to an isodiametric growth of the cells, occurs at a late stage in germination, immediately before the differentiation stage (germ-tube emergence). An additional observation was that the concentrations of dbut-cAMP, $N^{6}$-benzoyl-cAMP and SQ 65,442 needed to promote the total effect upon morphology were lowered threefold, 1.5-fold and threefold respectively when the compounds were added immediately before germ-tube emergence.

\section{Effect of CAMP analogues and SQ 65,442 under diverse nutritional and environmental conditions}

The experiments described so far and by Pereyra et al. (1992) were performed with sporangiospores growing aerobically in a defined medium with glucose (DMG). 
Table 2. Morphopoietic effect under different nutritional and ambient conditions

M. rouxii sporangiospores were grown in the various culture media with the addition of the indicated compounds; morphologies were observed after $16 \mathrm{~h}$ aerobic growth, $30 \mathrm{~h}$ anaerobic growth and $24 \mathrm{~h}$ after shifting from anaerobic to aerobic growth. Abbreviations for morphologies are the same as Table 1 . Y, yeast-like cells.

\begin{tabular}{|lll|}
\hline Culture medium & \multicolumn{1}{c|}{ Added compound } & Morphology \\
\hline Air atmosphere & & \\
DMM & None & $\mathrm{M}$ \\
& $0 \cdot 15 \mathrm{mM}$ dbut-cAMP & $\mathrm{T}$ \\
DMG & None & $\mathrm{M}$ \\
& $0 \cdot 15 \mathrm{mM}$ dbut-cAMP & $\mathrm{T}$ \\
DMCG & None & $\mathrm{M}$ \\
& $3 \mathrm{mM}$ dbut-cAMP & $\mathrm{T}$ \\
YPG & None & $\mathrm{M}$ \\
& $10 \mathrm{mM}$ dbut-cAMP & $\mathrm{P}$ \\
& $0 \cdot 1 \mathrm{mM}$ SQ 65,442 & $\mathrm{~T}$ \\
$\mathrm{CO}$ atmosphere $_{2}$ & & \\
YPG & None & $\mathrm{Y}^{*}$ \\
& $10 \mathrm{mM}$ dbut-cAMP & $\mathrm{Y}$ \\
Shift CO $\rightarrow \mathrm{O}_{2}$ & $0 \cdot 1 \mathrm{mM}$ SQ 65,442 & $\mathrm{~T}^{*}$ \\
YPG $\rightarrow$ DMG $^{*}$ & None & \\
& $0 \cdot 15 \mathrm{mM}$ dbut-cAMP & $\mathrm{P}^{*}$ \\
& $1 \mathrm{mM}$ dbut-cAMP & $\mathrm{T}^{*}$ \\
\hline
\end{tabular}

* Representative images of these stages are shown in Fig. 2.

We were interested in assaying whether the impairment of polarized growth promoted by cAMP analogues was also observed under different growth conditions. The media used for aerobic growth were the standard defined medium with glucose (DMG), the same medium with maltose as the carbon source (DMM), the Casamino acid-enriched medium with glucose (DMCG) and the classical rich medium (YPG). For anaerobic growth under $\mathrm{CO}_{2}$ atmosphere, only YPG medium was suitable, since yeast-like growth does not occur in defined medium (Bartnicki-García \& Nickerson, 1962) and spores germinating anaerobically in DMCG bud scarcely and therefore are an unsuitable model in which to detect isodiametric growth. Yeast-hyphal phase transitions were performed by harvesting yeast-like cells coming from an anaerobic culture in YPG, and aerating them in defined DMG medium. The results, summarized in Table 2, with representative morphologies being shown in Fig. 2, indicate that under aerobic conditions, the addition of either dbut-cAMP or SQ 65,442 promotes isodiametric growth under all the nutritional conditions. It was observed that the richer the culture medium, the higher the concentration of dbut-cAMP needed to attain the morphological effect. With YPG, only partial effects (not shown) could be observed at the highest assayed concentration of dbut-cAMP $(10 \mathrm{mM})$. Under anaerobic growth conditions in rich YPG medium, no effect was

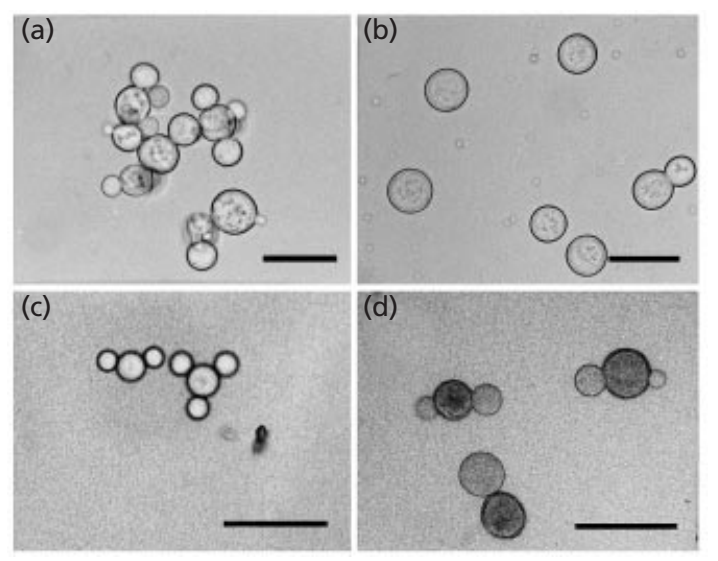

Fig. 2. Morphology of $M$. rouxii in anaerobiosis and during the anaerobic to aerobic shift transition. (a, b) Yeast-like cells after $30 \mathrm{~h}$ anaerobic growth in YPG in the absence (a) and in the presence (b) of $0.1 \mathrm{mM}$ SQ 65,442 . (c) Yeast-like cells after $15 \mathrm{~h}$ growth in YPG. (d) Cells observed $24 \mathrm{~h}$ after the shift of yeast cells from (c) into air in DMG medium in the presence of $1 \mathrm{mM}$ dbut-CAMP. Bars, $40 \mu \mathrm{m}$.

observed with $10 \mathrm{mM}$ dbut-cAMP. However, in the presence of $0 \cdot 1 \mathrm{mMSQ} 65,442$, growth was isodiametric, although with a slight impairment (Fig. 2b). For the experiment where cultures were shifted from anaerobiosis to aerobiosis, shown in Table 2, DMG medium was used for the aerobic condition in order to observe a good effect of the added cAMP analogue. The total effect was attained at $1 \mathrm{mM}$ dbut-cAMP. The images shown in Fig. 2(c, d) show that $24 \mathrm{~h}$ after the shift to aerobiosis, no more buds are emitted and cells continue growing in a non-polarized form (dry weight was increased $2 \cdot 5$-fold during the shift). An intense pigmentation of the cells was also observed.

\section{Culture medium and cell parameters at emergence time}

While analysing the effect of cAMP analogues on the morphology adopted by the sporangiospores cultured in different media, it was observed that the poorer the medium, the lower the concentration of cAMP analogue needed to promote a complete effect (as shown above in Table 2), the earlier the germination time and the smaller the diameter of the rounded cell at the time of germ-tube emergence. Table 3 shows a quantitative analysis of these differences and Fig. 3 shows representative images. The relative ratio between the volumes of the cells at this time, calculated from their diameter, was equivalent to the ratios of their dry weight or protein content, indicating that cell growth could account for the difference in cell diameter and volume. Cells grown in DMM germinate at $3.5 \mathrm{~h}$ with a volume which is 0.66-fold of that of cells growing in DMG, which germinate at $5 \cdot 5 \mathrm{~h}$. Cells grown in YPG are 5.7fold larger than the ones grown in standard DMG and show germ-1 tube emergence at $7 \mathrm{~h}$ of growth. 
Table 3. Culture medium and cell parameters at emergence time

Sporangiospores were inoculated at $1 \times 10^{6} \mathrm{ml}^{-1}$ in the different media and growth was continued until $50 \%$ of the cells had begun germ-tube emergence (emergence time). Cultures of $4 \mathrm{ml}$ were used for microscopic observation, $40 \mathrm{ml}$ for dry weight and protein determination, and 100-500 $\mathrm{ml}$ for enzymic measurements. Data are expressed as mean \pm SEM. ND, Not done.

\begin{tabular}{|c|c|c|c|c|c|c|c|}
\hline $\begin{array}{l}\text { Growth } \\
\text { medium }\end{array}$ & $\begin{array}{c}\text { Emergence } \\
\text { time }(h)\end{array}$ & $\begin{array}{l}\text { Diameter* } \\
\qquad(\mu \mathrm{m})\end{array}$ & $\begin{array}{c}\text { Volume } † \\
\qquad\left(\mu \mathrm{m}^{3}\right)\end{array}$ & $\begin{array}{c}\text { Dry wt }[\mathrm{mg} \\
\left.\left(4 \times 10^{7} \text { cells }\right)^{-1}\right]\end{array}$ & $\begin{array}{c}\text { Protein }[\mathrm{mg} \\
\left.\left(4 \times 10^{7} \text { cells }\right)^{-1}\right]\end{array}$ & $\begin{array}{c}\text { Specific } \\
\text { activity PKA } \neq \\
\left(\mathrm{U} \mathrm{mg}^{-1}\right)\end{array}$ & $\begin{array}{c}\text { Total activity } \\
\text { PKA } \mathbb{S}\left[\mathrm{U}\left(10^{6}\right.\right. \\
\left.\text { cells })^{-1}\right]\end{array}$ \\
\hline DMM & $3 \cdot 5$ & $6 \cdot 85 \pm 0 \cdot 07$ & $168 \pm 5$ & $4 \cdot 4 \pm 0 \cdot 1$ & ND & $4 \cdot 3 \pm 0 \cdot 9$ & $41 \pm 15$ \\
\hline DMG & $5 \cdot 5$ & $7 \cdot 85 \pm 0 \cdot 07$ & $253 \pm 7$ & $6 \cdot 4 \pm 0 \cdot 1$ & $1 \cdot 6 \pm 0 \cdot 1$ & $5 \cdot 0 \pm 0 \cdot 3$ & $102 \pm 5$ \\
\hline YPG & 7 & $14.03 \pm 0.06$ & $1446 \pm 17$ & $38 \cdot 4 \pm 0 \cdot 1$ & $10 \cdot 8 \pm 0 \cdot 1$ & $4 \cdot 3 \pm 0 \cdot 9$ & $320 \pm 20$ \\
\hline
\end{tabular}

* Measured on 100 cells per culture.

† Calculated from the measured cell diameter.

$\ddagger$ Measured in crude extracts in the presence of $10 \mu \mathrm{m}$ cAMP as described in Methods.

$\$$ Calculated from the specific activity, the total extract volume and the number of cells processed.

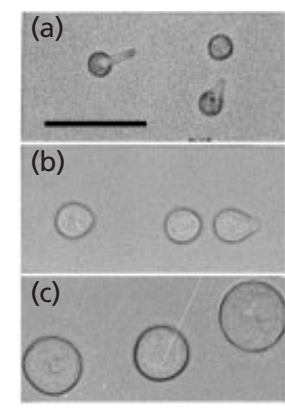

Fig. 3. Cells at the time of germ-tube emergence in different growth media. Sporangiospores were inoculated at $1 \times 10^{6} \mathrm{ml}^{-1}$ in the different media and growth was continued until $50 \%$ of the cells had begun germ-tube emergence. (a) DMM at $3.5 \mathrm{~h}$, (b) DMG at $5.5 \mathrm{~h}$, (c) YPG at $7 \mathrm{~h}$. Bar, $22 \mu \mathrm{m}$.

These results indicate that in $M$. rouxii, differentiation and growth are two processes that are not linked. Studies from both plant systems and Drosophila indicate that there may be a weak link between cell-cycle progression and morphogenesis (Edgar \& O'Farrell, 1989; Hemerly et al., 1995; Doerner et al., 1996), while recent studies in Aspergillus nidulans indicate an interaction between the two processes (Ye et al., 1999)

\section{PKA and germination}

We have previously measured and reported (Rossi \& Moreno, 1994) the specific activity of PKA during germination of sporangiospores in YPG rich medium. The methodological considerations for validating the assay of PKA activity in the presence of an exogenous saturating concentration of cAMP as a measure of total PKA levels was also given. The results indicated that total activity of PKA in sporangiospores inoculated in YPG decreased immediately after the onset of germination, following a transient increase in cAMP levels
(Rossi \& Moreno, 1994). After this stage, the total specific activity of PKA decreased in parallel with the increase in total protein and volume. A significant increase in the synthesis of regulatory and catalytic subunits to form the holoenzyme was not apparent until right before germ-tube emergence. From that time onwards the total specific activity for PKA, in the presence of cAMP, was more or less constant (Fig. 4c). We were interested in investigating whether this variation in PKA total activity also occurred when the cells were grown in more defined media, to evaluate whether PKA activity could be correlated with growth or differentiation processes. Fig. 4 ( $a$ and $b$ ) shows the variations in the levels of PKA total specific activity when spores were grown in DMM or DMG, respectively. The results show that a decrease in the activity of PKA is observed at the beginning of the germination process, independent of the growth medium used. This result was predictable, since it correlates with a transient peak of cAMP, occurring very shortly after inoculation of the spores in the growth medium. After this first decrease in PKA total specific activity, the extent of the decrease was inversely correlated with the growth of the culture. The poorer the medium, the less the PKA activity decreased. This result fits into the following interpretation: if during the first stages of growth the synthesis of PKA subunits does not go in parallel with the synthesis of total proteins, a decrease in the specific activity would be more severe in the cases where total growth is more evident (YPG $>$ DMG $>$ DMM). It is notable that in either DMG or YPG, total specific activity of PKA begins to increase significantly at germtube emergence. When cells were grown on DMM, a net increase is not observed, but shortly before germ-tube emergence, the specific activity stops decreasing and remains constant. Since, at this stage, growth begins to increase significantly, a constant level of PKA specific activity necessarily means an increase in the synthesis of the enzyme. It was surprising to observe that the specific activity of PKA in the three media at the time of germ- 

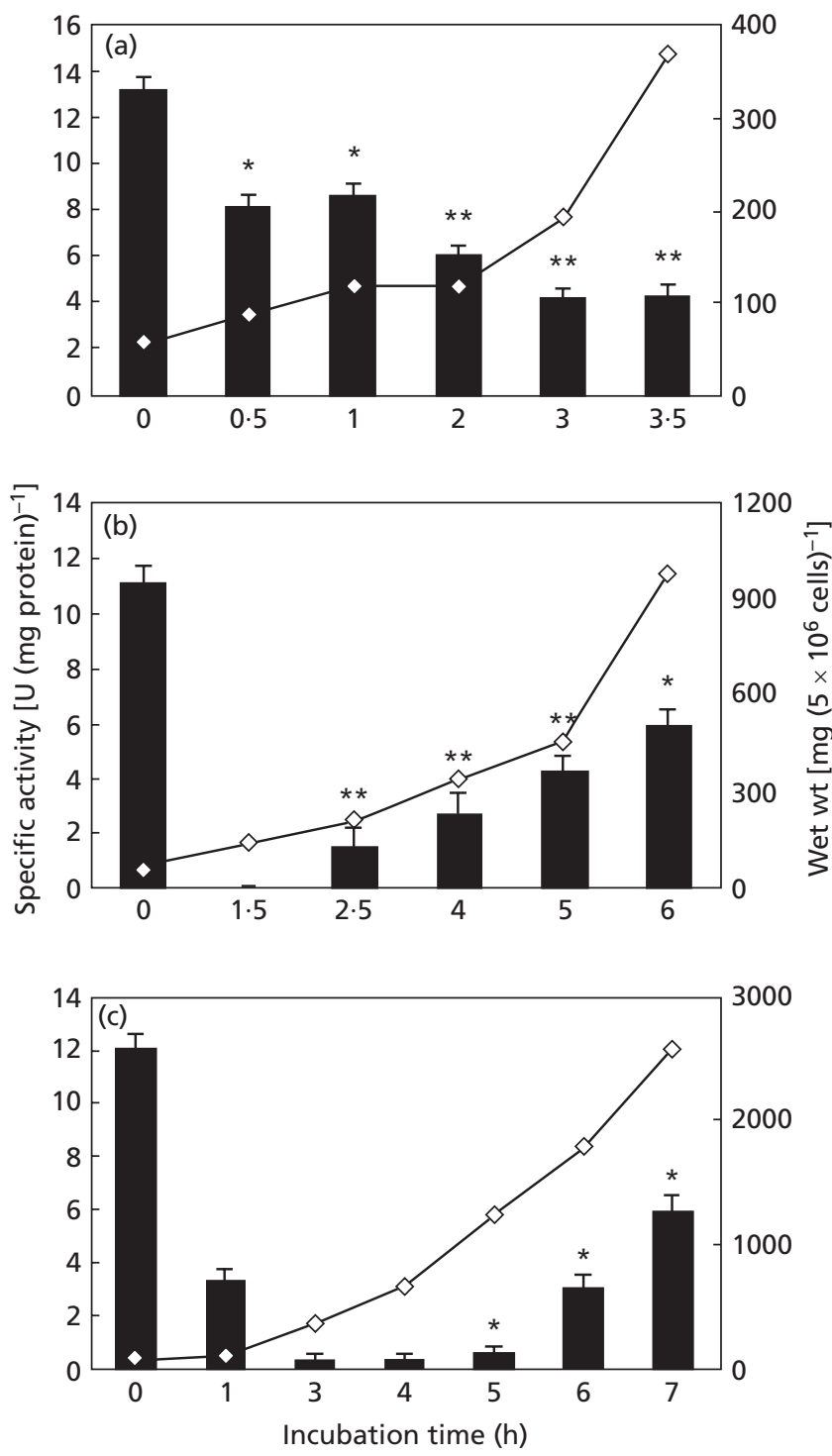

Fig. 4. Specific activity of PKA during germination. Spores were inoculated at $10^{6} \mathrm{ml}^{-1}$ in medium DMM (a), DMG (b) and YPG (c). Germination was followed by microscopy; growth by dry weight ( $\diamond$, right axis) and PKA specific activity was measured in crude extracts (bars, left axis). PKA specific activities are expressed as mean $\pm \operatorname{SEM}(*, P<0.01 ; * *, P<0.001$; ANOVA followed by Dunnett's test).

tube emergence was very similar. To analyse these data more carefully, an experiment was performed in which the cultures under the three growth conditions were performed in parallel, with the same batch of spores, and the extracts for enzymic assays were processed side by side, with cells harvested from each culture at the corresponding emergence time (as defined in Table 3). The total specific activity of PKA attained at the time of germ-tube emergence under the three culture conditions was surprisingly alike (Table 3 ). However, if we recalculate the data to express them as the total units of PKA per $10^{6}$ cells (Table 3 ) it can be seen that the variation is in accordance with the difference in size and growth of the cells grown in the different media; the total activity of PKA per cell unit is much less in a small cell (DMM) than in a large cell (YPG).

From the results described in Fig. 4 and Tables 2 and 3 we can establish two correlations: 1 , the time of germtube emergence correlates with the time of attainment of a threshold level of total PKA specific activity; 2, the concentration of dbut-cAMP needed to promote isodiametric growth correlates with the total amount of PKA to be activated per cell (Table 2). We can include in this last correlation the observation of Pereyra et al. (1992), that more dbut-cAMP was needed to maintain the impairment of polarized growth in cultures with an inoculum of $10^{4}$ cells $\mathrm{ml}^{-1}$ than in cultures from $10^{6}$ cells $\mathrm{ml}^{-1}$, since the cells grown from the lower inoculum are much larger in volume (due to the higher number of generations per cell) and the amount of PKA per cell was accordingly greater.

We are therefore tempted to speculate that a threshold concentration of PKA must be attained in order to elicit the germ-tube emergence. If one divides the germination process in two - the growth stage and the differentiation stage, that occur intermingled - it seems that the PKA specific activity does not correlate with growth, as cell volume and total protein do, but with differentiation. Thus, the poorer the culture medium, the slower the growth process and the earlier the threshold specific activity of PKA is attained. In accordance with these results, it has been recently reported that the levels of another family of proteins involved in signal transduction, the Ras proteins in Mucor racemosus, do not correlate with growth but with differentiation (Roze $e t$ al., 1999).

\section{Testing of the hypothesis}

If the hypothesis that a threshold concentration of PKA must be attained in order to elicit germ-tube emergence is correct, we could predict the results to be observed when shifting a culture from a poor medium into a rich medium and vice versa, regarding time of germ-tube emergence and sensitivity to the morphological effect of dbut-cAMP. One of the predictions would be that when shifting a culture, before germ-tube emergence, from a poor medium into a rich medium the growth process should be favoured and therefore the specific activity of PKA should begin to decrease; this would have as a consequence a delay in the emergence of the germ tube and a necessity for higher concentrations of dbut-cAMP to promote isodiametric growth. Another prediction would be that, on the contrary, a shift from rich medium to poor medium should favour the differentiation process with an increase in PKA specific activity, an anticipation of the germination time and an increased sensitivity to dbut-cAMP. The results, shown in Table 4, are exactly the ones predicted. When shifting the culture from DMG to YPG the germination time was delayed and the sensitivity to dbut-cAMP was decreased, and 
Table 4. Growth medium, emergence time and dbut-cAMP sensitivity

Cultures $(4 \mathrm{ml})$ were prepared for each of the two protocols in either DMG or YPG; after $5 \mathrm{~h}$ growth cells were collected by filtration and resuspended in $4 \mathrm{ml}$ of each of the indicated media with or without dbut-cAMP, as indicated. The total incubation time was $16 \mathrm{~h}$. Data shown are representative of three experiments performed with independent sporangiospore preparations. NA, Not applicable. Abbreviations for morphology are as Table 1.

\begin{tabular}{|llcc|}
\hline $\begin{array}{l}\text { First incubation } \\
\mathbf{5} \mathbf{~ h})\end{array}$ & Second incubation $(\mathbf{1 1} \mathbf{h})$ & $\begin{array}{c}\text { Emergence } \\
\text { time }^{*}(\mathbf{h})\end{array}$ & $\begin{array}{c}\text { Morphology } \\
\text { at } \mathbf{1 6} \mathbf{~ h}\end{array}$ \\
\hline DMG & DMG & $5 \cdot 5$ & $\mathrm{M}$ \\
& $\mathrm{DMG}+0 \cdot 15 \mathrm{mM}$ dbut-cAMP & $\mathrm{NA}$ & $\mathrm{T}$ \\
& YPG & $7-8$ & $\mathrm{M}$ \\
YPG & YPG $+1 \mathrm{mM}$ dbut-cAMP & 8 & $\mathrm{M}$ \\
& YPG & 7 & $\mathrm{M}$ \\
& YPG $+1 \mathrm{mM}$ dbut-cAMP & 7 & $\mathrm{M}$ \\
& $\mathrm{DMG}$ & 6 & $\mathrm{M}$ \\
& $\mathrm{DMG}+0 \cdot 15 \mathrm{mM}$ dbut-cAMP & 6 & $\mathrm{P}$ \\
& $\mathrm{DMG}+1 \mathrm{mM}$ dbut-cAMP & $\mathrm{NA}$ & $\mathrm{T}$ \\
\hline
\end{tabular}

* Time at which $50 \%$ of the cells had emitted a germ tube.

exactly the opposite occurred when the shift was done from a rich medium (YPG) to a poorer medium (DMG).

Additional support to this hypothesis comes from the anaerobic to aerobic shift experiments shown in Table 2 , where $0 \cdot 15 \mathrm{mM}$ dbut-cAMP was not enough to promote a total effect, as would have been predicted for a culture coming from a rich medium. An increase in the dbut-cAMP concentration needed to obtain effect in yeast-to-hypha morphogenesis when using rich medium, as compared to defined medium, has already been reported for M. racemosus (Larsen \& Sypherd, 1974).

\section{Conclusions}

The results presented in this work, taken as a whole, suggest that PKA is involved in $M$. rouxii polarized growth, and that morphogenesis and growth are two unlinked processes. The evidence can be summarized as follows. Impairment of polarized growth was obtained with cAMP analogues that are good in vitro PKA activators such as the $N^{6}$-cAMP analogues and by a very good $M$. rouxii PDE inhibitor. The lack of polarized growth observed in the presence of cAMP analogues was obtained under all the nutritional and environmental conditions studied, and was independent of the time of addition of the cAMP analogue to the culture medium. The effect was observed even when adding the compounds very shortly before germ-tube emergence. At this time the specific activity of regulatory and catalytic subunits is high, while being very low or almost undetectable at earlier times of germination. The time of germ-tube emergence correlated with the time of attainment of a threshold level of PKA specific activity. The concentration of dbut-cAMP needed to impair polarized growth correlated with the total amount of
PKA to be activated per cell. All the observed effects, namely isodiametric growth, increased pigmentation, increased cell fragility and lack of adhesiveness, have been proposed to be related to the cAMP signaltransduction pathway in other systems.

The fact that an effect of cAMP analogue on morphology is still observed when added after germ-tube emergence suggests that polarized growth is not the result of a commitment decided in a previous step but that is a result of a regulatory process that must be maintained throughout and that PKA participates in this maintenance. Support for this statement is seen in the immediate reversion from isodiametric to polarized growth upon removal of the culture medium containing the cAMP analogue and replacement with fresh medium without analogue (Pereyra et al., 1992).

We have now established a model system in which to investigate the downstream targets of PKA in relation to polarized growth. Apical growth is a dynamic process involving the continual synthesis and deposition of cell wall at the apex, concomitant with the forward movement of cytoplasm and independent movement of vesicles, nuclei, mitochondria and other organelles, as they maintain their positions relative to the extending tip (Jackson \& Heath, 1993). Over the last few years it has become increasingly clear that actin is involved in a variety of the processes that result in tip growth (Heath, 1994). Preliminary results obtained with $M$. rouxii (Sabanero, 1994 and our unpublished results) indicate that in the presence of cytochalasin, the morphology adopted by the cells regarding isodiametric growth and cell-wall width are similar to the results obtained with cAMP analogues. We are therefore tempted to speculate that PKA might be involved in the regulation of actin microfilament organization. 


\section{ACKNOWLEDGEMENTS}

This work was supported by grants from the Third World Academy of Sciences (TWAS), University of Buenos Aires, Agencia Nacional de Promoción Científica y Tecnológica and Consejo Nacional de Investigaciones Científicas y Técnicas. C. M. had a student fellowship from Fundación Antorchas.

\section{REFERENCES}

Alspaugh, J. A., Perfect, J. R. \& Heitman, J. (1998). Signal transduction pathways regulating differentiation and pathogenicity of Cryptococcus neoformans. Fungal Genet Biol 25, 1-14.

Bartnicki-García, S. (1990). Role of vesicles in apical growth and a new mathematical model of hyphal morphogenesis. In Tip Growth in Plant and Fungal Cells, pp. 211-232. Edited by I. B. Heath. San Diego: Academic Press.

Bartnicki-García, S. (1996). The hypha: unifying thread of the fungal kingdom. In A Century of Mycology, pp. 105-133. Edited by B. C. Sutton. Cambridge: Cambridge University Press.

Bartnicki-García, S. \& Nickerson, W. J. (1962). Nutrition, growth and morphogenesis of Mucor rouxii. J Bacteriol 83, 841-858.

Bradford, M. (1976). A rapid and sensitive method for the quantitation of microgram quantities of protein utilizing the principle of protein-dye binding. Anal Biochem 72, 248-254.

Braunmann, T., Erneux, C., Petridis, G., Stohrer, W. \& Jastorff, B. (1986). Hydrolysis of cyclic nucleotides by a purified cGMPphosphodiesterase; structural requirements for hydrolysis. Biochim Biophys Acta 871, 199-206.

Bruno, K. S., Aramayo, R., Minke, P. F., Metzenberg, R. L. \& Plamann, M. (1996). Loss of growth polarity and mislocalization of septa in a Neurospora mutant altered in the regulatory subunit of cAMP-dependent protein kinase. EMBO J 15, 5772-5782.

Dandekar, S. \& Modi, V. V. (1980). Involvement of cyclic AMP in carotenogenesis and cell differentiation in Blakeslea trispora. Biochim Biophys Acta 628, 398-406.

Doerner, P., Jorgensen, J., You, R., Steppuhn, J. \& Lamb, C. (1996). Control of root growth and development by cyclin expression. Nature 380, 520-523.

Edgar, B. A. \& O’Farrell, P. H. (1989). Genetic control of cell division patterns in the Drosophila embryo. Cell 57, 177-187.

Glass, W. F., Jr \& Kreisberg, J. I. (1993). Regulation of integrinmediated adhesion at focal contacts by cyclic AMP. J Cell Physiol 157, 296-306.

Guthmann, M., Pastori, R. \& Moreno, S. (1990). Polyamines and basic proteins stimulate activation by cAMP and catalytic activity of Mucor rouxii cAMP dependent protein kinase. Cell Signal 2, 395-402.

Haidle, C. W. \& Storck, R. (1966). Control of dimorphism in Mucor rouxii. J Bacteriol 92, 1236-1244.

Hamer, J. E. \& Talbot, N. J. (1998). Infection-related development in the rice blast fungus Magnaporthe grisea. Curr Opin Microbiol 1, 693-697.

Heath, I. B. (1994). The cytoskeleton in hyphal growth, organelle movements and mitosis. In The Mycota: a Comprehensive Treatise on Fungi as Experimental Systems for Basic and Applied Research, vol. 1, Growth, Differentiation and Sexuality, pp. 43-65, Edited by J. H. G. Wessels \& F. Meinhardt. Berlin: Springer.

Hemerly, A., Engler, J., Bergounioux, C., Montagu, M., Engler, G., Inze, D. \& Ferrerira, P. (1995). Dominant negative mutants of the $\mathrm{Cdc} 2$ kinase uncouple cell division from iterative plant development. EMBO J 14, 3925-3936.
Hohl, N., Galland, P. \& Senger, H. (1992). Altered pterin patterns in photobehavioral mutants of Phycomyces blakesleeanus. Photochem Photobiol 55, 239-245.

Jackson, S. L. \& Heath, I. B. (1993). Roles of calcium ions in hyphal tip growth. Microbiol Rev 57, 367-382.

Jones, B. E. \& Bu'Lock, J. D. (1977). The effect of $\mathrm{N}^{6}, \mathrm{O}^{2^{\prime}}$-dibutyryl adenosine-3',5'-cyclic monophosphate on morphogenesis in mucorales. J Gen Microbiol 103, 29-36.

Kronstad, J. W. (1997). Virulence and cAMP in smuts, blasts and blights. Trends Plant Sci 2, 193-200.

Kronstad, J., De Maria, A., Funnell, D., Laidlaw, R. D., Lee, N., Moniz de Sá, M. \& Ramesh, M. (1998). Signalling via cAMP in fungi: interconnections with mitogen-activated protein kinase pathways. Arch Microbiol 170, 395-404.

Larsen, A. D. \& Sypherd, P. (1974). Cyclic adenosine $3^{\prime}, 5^{\prime}$ monophosphate and morphogenesis in Mucor racemosus. I Bacteriol 117, 432-438.

Madhani, H. D. \& Fink, G. R. (1998). The control of filamentous differentiation and virulence in fungi. Trends Cell Biol 8, 348-353.

Money, N. P. (1994). Osmotic adjustment and the role of turgor in mycelial fungi. In The Mycota: a Comprehensive Treatise on Fungi as Experimental Systems for Basic and Applied Research, vol. 1, Growth, Differentiation and Sexuality, pp. 67-88, Edited by J. H. G. Wessels \& F. Meinhardt. Berlin: Springer.

Moreno, S. \& Passeron, S. (1980). Further studies on cAMPdependent protein kinase from the dimorphic fungus Mucor rouxii. Arch Biochem Biophys 199, 321-330.

Moreno, S., Pastori, R. \& Passeron, S. (1983). Protein kinase of Mucor rouxii: unshielding of new cyclic AMP binding sites upon dissociation of the ternary complex holoenzyme-cyclic AMP. Mol Cell Biochem 52, 13-16.

Øgreid, D., Ekanger, R., Suva, R., Miller, J., Sturm, P., Corbin, J. D. \& Døskeland, S. O. (1985). Activation of protein kinase isozymes by cyclic nucleotide analogues used singly or in combination. Eur J Biochem 150, 219-227.

Orlowski, M. (1991). Mucor dimorphism. Microbiol Rev 55, 234-258.

Orlowski, M. (1995). Gene expression in Mucor dimorphism. Can J Bot 73, S326-S334.

Paveto, C., Passeron, S., Corbin, J. D. \& Moreno, S. (1989). Two different intrachain cAMP sites in the cAMP-dependent protein kinase from the dimorphic fungus Mucor rouxii. Eur J Biochem 179, 429-434.

Pereyra, E., Zaremberg, V. \& Moreno, S. (1992). Effect of dibutyryl-cAMP on growth and morphology of germinating Mucor rouxii sporangiospores. Exp Mycol 16, 93-101.

Roskoski, R. (1983). Assay of protein kinase. Methods Enzymol 99, 3-6.

Rossi, S. \& Moreno, S. (1994). Regulation of protein kinase A subunits during germination of Mucor rouxii sporangiospores. Eur J Biochem 222, 501-506.

Roze, L. V., Mahanti, N., Mehigh, R., McConnell, D. G. \& Linz, J. E. (1999). Evidence that MRas1 and MRas3 proteins are associated with distinct cellular functions during growth and morphogenesis in the fungus Mucor racemosus. Fungal Genet Biol 28, 171-180.

Sabanero, M. (1994). Effects of cytochalasins on growth of Mucor rouxii. Microbios 80, 91-97.

Sietsma, J. H. \& Wessels J. H. G. (1994). Apical wall biogenesis. In The Mycota, vol. 1, pp. 126-141, Edited by J. H. G. Wessels \& F. Meinhardt. Berlin: Springer. 
Tomes, C. \& Moreno, S. (1990). cAMP analogs and selective inhibitors used to study low $K_{\mathrm{m}}$ Mucor rouxii cAMP phosphodiesterase. Int J Biochem 22, 1047-1051.

Tomes, C., Rossi, S. \& Moreno, S. (1993). Isobutyl-methyl-xanthine and other classical cyclic nucleotide phosphodiesterase inhibitors affect cAMP-dependent protein kinase activity. Cell Signal 5, 615-621.

Van Haastert, P. J. M., Dijkgraaf, P. A. M., Konijn, T. M., Garcia Abbad, E., Petridis, G. \& Jastorff, B. (1983). Substrate specificity of cyclic nucleotide phosphodiesterase from beef heart and from Dictyostelium discoideum. Eur J Biochem 131, 659-666.

Van Lookeren-Campagne, M. M., Villalba Díaz, F., Jastorff, B., Winkler, E., Genieser, H. \& Kessin, R. H. (1990). Characterization of the yeast low $K_{\mathrm{m}}$ phosphodiesterase with cAMP analogues: applications in mammalian cells that express the yeast PDE2 gene. J Biol Chem 265, 5847-5854.

Yang, S. \& Dickman, M. B. (1999). Colletotrichum trifolii mutants disrupted in the catalytic subunit of cAMP-dependent protein kinase are nonpathogenic. Mol Plant-Microbe Interact 12, 430-439.

Ye, X. S., Lee, S., Wolkow, T. D., McGuire, S. L., Hamer, J. E., Wood, C. G. \& Osmani, S. A. (1999). Interaction between developmental and cell cycle regulators is required for morphogenesis in Aspergillus nidulans. EMBO J 18, 6994-7001.

Received 20 January 2000; revised 3 May 2000; accepted 15 May 2000. 